\title{
Pattern and predictors of maternal care-seeking practices for severe neonatal jaundice in Nigeria: a multi-centre survey
}

\author{
Chinyere V Ezeaka ${ }^{1}$, Rosemary O Ugwu², Mariya Mukhtar-Yola ${ }^{3}$, Ekanem N Ekure ${ }^{1}$ and Bolajoko O Olusanya ${ }^{4 *}$
}

\begin{abstract}
Background: Nigeria is frequently associated with disproportionately high rates of severe neonatal jaundice (NNJ) underpinned by widespread Glucose-6-phosphate dehydrogenase (G6PD) deficiency. Timely and appropriate treatment of NNJ is crucial for preventing the associated morbidity and neuro-developmental sequelae. Since mothers are likely to be the first mostly to observe the onset of severe illness in their newborns, we set out to identify the pattern and predictors of maternal care-seeking practices for NNJ in three culturally-distinct settings in Nigeria.
\end{abstract}

Methods: A multi-centre study was conducted among women attending antenatal clinics in Abuja, Lagos and Port Harcourt from October 2011 to April 2012 using a pretested questionnaire. Predictors of awareness of NNJ, accurate recognition of NNJ, use of potentially harmful therapies and preference for future hospital treatment were determined with multivariate logistic regressions.

Results: Of the 488 participants drawn from the three locations, 431 (88.3\%) reported awareness of NNJ, predominantly (57.8\%) attributable to professional health workers. A total of 309 (63.3\%) mothers with prior knowledge of NNJ claimed they could recognise NNJ, but $270(87.4 \%)$ from this group accurately identified the features of NNJ. Multiparous mothers (Adjusted odds ratio, AOR:4.05; 95\% Cl:1.75-9.36), those with tertiary education (AOR:1.91; Cl:1.01-3.61), and those residing in Lagos (AOR:2.96; Cl:1.10-7.97) were more likely to have had prior knowledge of NNJ. Similarly, multiparous mothers (AOR:2.38; Cl:1.27-4.46) and those with tertiary education (AOR:1.92; Cl:1.21-3.05) were more likely to recognise an infant with jaundice accurately. Mothers educated by health workers were $40 \%$ less likely to resort to potentially harmful treatment for NNJ (AOR:0.60; Cl:0.39-0.92) but more likely to seek hospital treatment in future for an infant suspected with jaundice (AOR:1.88; Cl:1.20-2.95).

Conclusions: Women with tertiary education and multiparous mothers who attend routine antenatal clinics are more likely than less educated women, to be associated with appropriate care-seeking practices for infants with NNJ regardless of the socio-cultural setting. Systematic efforts by professional health workers are warranted, as part of routine antenatal care, to engage other groups of mothers especially those likely to indulge in self-use of potentially harmful therapies.

Keywords: Neonatal jaundice, Newborn care, Health-seeking behaviour, Health promotion, Haemolytic agents, Self-medication, Developing countries

\section{Background}

Severe neonatal jaundice or hyperbilirubinaemia (NNJ) resulting from excessive unconjugated bilirubin levels is the commonest or one of the five leading conditions for hospital (re)admissions in the first week of life in many low-income countries [1]. If poorly managed, severe

\footnotetext{
*Correspondence: boolusanya@aol.com

${ }^{4}$ Centre for Healthy Start Initiative, Dolphin Estate, Ikoyi, Lagos, Nigeria

Full list of author information is available at the end of the article
}

NNJ may result in deaths [2-5], or various lifelong neurodevelopmental impairments such as intellectual deficits, cerebral palsy, sensorineural hearing loss, epilepsy and behavioural problems among survivors [5-7].

In the majority of newborns with uncomplicated vaginal delivery, NNJ commonly manifests 48 hours after birth and hospital discharge. Mothers are thus, likely to be the first to observe the onset of NNJ in affected infants. Poor or lack of understanding of this condition is

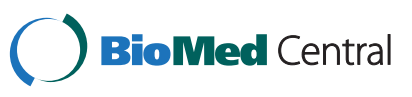


likely to result in risky delays, mismanagement and complications with adverse psycho-social consequences for the affected mothers [8]. With appropriate education, mothers can reliably recognise the familiar discolouration of the sclera and mucous membranes and seek timely treatment [9]. Informed and appropriate careseeking practices by mothers are, therefore, recognised worldwide as an integral component of the effective management of NNJ.

The burden of NNJ underpinned by widespread Glucose-6-phosphate dehydrogenase (G6PD) deficiency has been extensively reported for several years in Nigeria [4,5,10-15]. About 5.5\% of all newborns are estimated to have clinically significant $\mathrm{NNJ}$ requiring phototherapy and/or exchange blood transfusion (EBT) in the country, probably one of the highest rates globally [16]. Most tertiary institutions are still overwhelmed with exceptionally high rates of EBT daily [17]. The role of local cultural practices in the (mis)management of NNJ has also been widely reported $[10,18]$. However, only limited studies have examined factors associated with appropriate careseeking disposition for NNJ among expectant mothers across distinct socio-cultural settings in Nigeria [19-21]. This multi-centre study, therefore, set out to assess the level of awareness and understanding of NNJ among pregnant mothers as well as identify predictors of appropriate care-seeking practices to facilitate early detection and intervention for infants at risk of severe NNJ in Nigeria.

\section{Methods}

This cross-sectional study was carried out at the three tertiary public hospitals located in Abuja (Northern Nigeria), Lagos (Southwest, Nigeria) and Port Harcourt (Southeast, Nigeria) between October 2011 and April 2012. The sites are described by their approximate geographical locations rather than geopolitical zones. Abuja is the administrative capital and the seat of the federal government while Lagos is the most commercially active city in Nigeria. Port Harcourt is the most prominent city in the oil producing Niger-Delta region of the country. The survey instrument was pretested among mothers in one of the tertiary centres between January and April 2009 , evaluated independently by a team of experienced paediatricians and appropriately revised into a concise one-page document for ease of administration before the commencement of the multi-centre study (Additional file 1). Three of the authors personally supervised the administration of the questionnaire at their respective centres having also contributed to the final construct of the questionnaire for comprehension and content validity. Medical and other terminologies were clearly explained by the interviewer to the participants especially those who were not literate. The required minimum sample size after allowing for $20 \%$ attrition at $95 \%$ confidence interval was 380. This was computed in Epi-Info 7.0 (CDC, Atlanta, USA) based on the total population of women in the three locations where the study was conducted as per the 2006 national census data and the weighted mean prevalence of 71.1\% derived from relevant local research [19-21].

Ethical approval was obtained from the Lagos University Teaching Hospital, Lagos, Nigeria (the lead/coordinating institution) for the study design which did not entail any prophylactic, diagnostic or therapeutic interventions. In line with the Helsinki Declaration [22], only mothers from whom informed consent was obtained were enrolled for the study. The questionnaire was administered to consecutive mothers who attended the antenatal clinic at each centre. The term "mothers" was used broadly in this study for first-time mothers and those already with children. The first part of the questionnaire included socio-demographic data of respondents such as maternal age, marital status, parity, ethnicity, religion, self and spouse's education, occupation, residential type (an indicator of neighbourhood influence) and home ownership (an indicator of economic status). The next part aimed to assess the knowledge of the mothers and the source of information, accurate recognition of NNJ, knowledge of the potential dangers or complications of severe NNJ, treatment modalities or preferences. The potential dangers considered included death or neuro-developmental delay or disability such as motor deficit, delayed milestones, mental retardation, speech defects or deafness. The third part sought to establish the respondent's experience with an infant with jaundice and the actions taken as well as possible future course of action if confronted with a jaundiced infant.

An overview of the socio-demographic characteristics of the respondents across the three centres was examined with descriptive statistics. Logistic regression models were used to predict factors significantly associated with four main outcomes. Firstly, we examined factors predictive of prior knowledge of NNJ among all respondents ( $n=488$ ). Secondly, we constructed three separate models to identify predictors of accurate recognition of NNJ, self-treatment with potentially harmful substances and future hospital visit for suspected NNJ among women with prior knowledge of NNJ ( $n=431)$. Maternal recognition of NNJ was considered as accurate if yellowish discolouration of the eyes and/or face and body skin along the cephalocaudal progression were mentioned. Two-tailed p-values equal to or less than 0.05 were considered as significant. However, selection of variables for the models was not restricted to those with significant outcomes from bivariate analysis but included those closely linked with maternal health seeking behaviour in previous local studies [19-21,23]. Strength of association in each model was estimated by adjusted odds ratios (AOR) and the 
corresponding 95\% confidence intervals (CI). Model calibration or goodness-of-fit was verified with the HosmerLemeshow test. Except for sample size calculation, IBM SPSS Statistics for Windows, Version 20.0 (Armonk, NY: IBM Corp) was used for all statistical analyses.

\section{Results}

\section{Characteristics of respondents}

A total of 488 women completed the questionnaire from the three centres out of which 57 (11.7\%) women said they had no knowledge of NNJ. Of the 431 women who have some knowledge of NNJ, 85 (19.7\%) were in Abuja, 136 (31.6\%) in Lagos and 210 (48.7\%) in Port Harcourt. The proportion of women who have not or have heard of NNJ among the respondents in each location is shown in Figure 1. The proportion of women who had no prior knowledge of $\mathrm{NNJ}$ among respondents was highest in Abuja (15.8\%) and lowest in Lagos (7.5\%). The socio-demographic profile of the women with prior knowledge of $\mathrm{NNJ}$ across the three locations is presented in Table 1. Majority of respondents were 20-35 years of age, married, had 2 or more children, belonged to one of the three major tribes (i.e. Hausa, Ibo and Yoruba), professed Christianity, had tertiary education and lived in self-contained but rented residences.

\section{Characteristics of respondents with knowledge of newborn jaundice}

Of all the 431 mothers with prior knowledge of NNJ, 249 (57.8\%) ascribed this information to health workers (doctors or nurses) as shown in Table 2. While 309 (71.7\%) mothers reported ability to recognise NNJ, only
$87.4 \%(270 / 309)$ of these mothers demonstrated accurate recognition of NNJ representing $62.6 \%$ of those who claimed prior knowledge of NNJ. A total of 240 mothers, representing $77.7 \%$ of mothers who reported their ability to recognise $\mathrm{NNJ}$ or $55.7 \%$ of those with reported prior knowledge of $\mathrm{NNJ}$ recognised the effect of $\mathrm{NNJ}$ as poor feeding, irritability, abnormal cry, abnormal body stretching or abnormal eye movement. Of all mothers with prior NNJ awareness, $314(72.8 \%)$ mothers cited the dangers of NNJ as either death, disability or both. Few (35 or $8.1 \%$ ) mothers attributed $\mathrm{NNJ}$ to infections, prematurity or $\mathrm{ABO} / \mathrm{Rh}$ incompatibilities. Although the vast majority (91.9\%) of the mothers planned to deliver the index pregnancies in hospitals, more than half (55.8\%) indicated the possible use of potentially harmful menthol substances either as treatment for NNJ or some other purposes.

\section{Care-seeking practices of mothers with knowledge of newborn jaundice}

Almost $30 \%$ of the mothers $(n=128)$ claimed to have had an infant with jaundice and health workers were the first to detect this condition in about $44.5 \%(n=57)$ of the affected infants (Table 3). Hospital admission, reported in $70(16.2 \%)$ mothers, was the most common intervention followed by exposure to sunlight by 38 (8.8\%) mothers. Although majority $(89.1 \%)$ of the mothers reported full recovery in the affected infants, 9 (7.0\%) mothers reported neonatal deaths and $3(2.3 \%)$ mothers reported recovery with some sequelae. The majority $(70.3 \%$ or $303 / 431)$ of mothers indicated that they would seek advice or hospital care if confronted again with a jaundiced infant. From this group, 96 (31.7\%) had an infant with jaundice. Up to $25 \%$

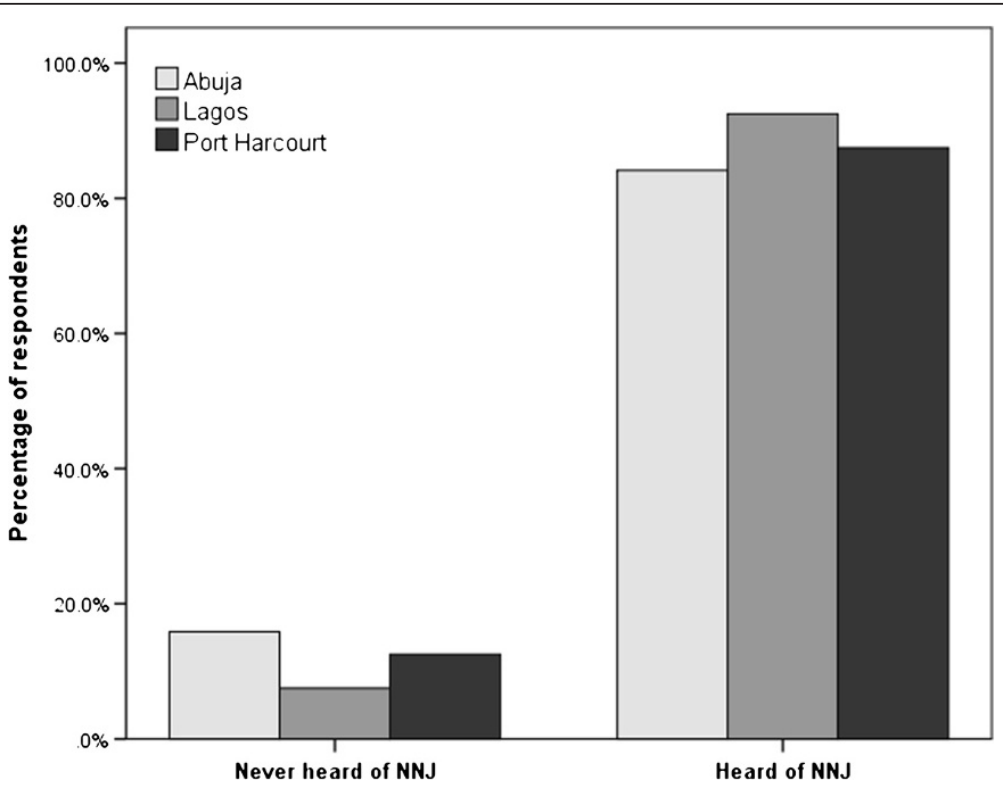

Figure 1 Proportion of respondents $(n=488)$ with or without prior knowledge of neonatal jaundice across the survey centres. 
Table 1 Characteristics of pregnant mothers enrolled for study at three centres $(n=431)$

\begin{tabular}{|c|c|c|c|c|}
\hline Factors & $\begin{array}{l}\text { Abuja } \\
n=85\end{array}$ & $\begin{array}{l}\text { Lagos } \\
n=136\end{array}$ & $\begin{array}{c}\text { Port Harcourt } \\
n=210\end{array}$ & $\begin{array}{l}\text { Total } \\
\text { n (\%) }\end{array}$ \\
\hline \multicolumn{5}{|l|}{ Maternal age (Years) } \\
\hline$<20$ & 0 & 2 & 0 & $2(0.5)$ \\
\hline $20-35$ & 85 & 100 & 199 & $384(89.1)$ \\
\hline$>35$ & 0 & 14 & 11 & $25(5.8)$ \\
\hline Unknown & 0 & 20 & 0 & $20(4.6)$ \\
\hline \multicolumn{5}{|l|}{ Marital status } \\
\hline Single & 5 & 3 & 10 & $18(4.1)$ \\
\hline Married & 77 & 133 & 198 & $408(94.7)$ \\
\hline Separated/Widow & 3 & 0 & 2 & $5(1.2)$ \\
\hline \multicolumn{5}{|l|}{ Parity } \\
\hline 0 & 3 & 58 & 24 & 85 (19.7) \\
\hline 1 & 28 & 39 & 56 & $123(28.5)$ \\
\hline 2 or more & 54 & 39 & 130 & $223(51.7)$ \\
\hline \multicolumn{5}{|l|}{ Ethnicity } \\
\hline Hausa & 20 & 17 & 19 & $56(13.0)$ \\
\hline Ibo & 25 & 42 & 58 & $125(29.0)$ \\
\hline Yoruba & 15 & 57 & 12 & $84(19.5)$ \\
\hline Others & 25 & 20 & 121 & 166 (38.5) \\
\hline \multicolumn{5}{|l|}{ Religion } \\
\hline Christianity & 76 & 111 & 204 & $391(90.7)$ \\
\hline Islam & 9 & 25 & 6 & $40(9.3)$ \\
\hline \multicolumn{5}{|l|}{ Education } \\
\hline Primary & 5 & 4 & 9 & $18(4.2)$ \\
\hline Secondary & 24 & 21 & 62 & $107(24.9)$ \\
\hline Technical & 10 & 9 & 24 & $43(10.0)$ \\
\hline Tertiary & 46 & 102 & 115 & $263(61.0)$ \\
\hline \multicolumn{5}{|l|}{ Education of spouse } \\
\hline Primary & 1 & 3 & 4 & $8(1.9)$ \\
\hline Secondary & 13 & 32 & 44 & 89 (20.6) \\
\hline Technical & 10 & 5 & 17 & $32(7.4)$ \\
\hline Tertiary & 61 & 96 & 145 & $302(70.1)$ \\
\hline \multicolumn{5}{|l|}{ Occupation } \\
\hline None & 9 & 12 & 46 & $67(15.5)$ \\
\hline Student & 1 & 12 & 20 & $33(7.7)$ \\
\hline Self-employed & 37 & 41 & 74 & $152(35.3)$ \\
\hline Formal Job & 32 & 56 & 65 & 153 (35.5) \\
\hline Unknown & 6 & 15 & 5 & $26(6.0)$ \\
\hline \multicolumn{5}{|l|}{ Residential type } \\
\hline Self-contained & 60 & 110 & 168 & $338(78.4)$ \\
\hline Shared & 15 & 26 & 40 & $81(18.8)$ \\
\hline Unknown & 10 & 0 & 2 & $12(27.8)$ \\
\hline
\end{tabular}

Table 1 Characteristics of pregnant mothers enrolled for study at three centres $(n=431)$ (Continued)

\begin{tabular}{lcccc}
\hline Home ownership status & & & & \\
Owned & 26 & 20 & 62 & $108(25.0)$ \\
Rented & 49 & 116 & 146 & $311(72.2)$ \\
Unknown & 10 & 0 & 2 & $12(27.8)$ \\
\hline
\end{tabular}

(32/128) of mothers with prior experience of an infant with jaundice may not seek hospital care, and about $18 \%$ (51/128) indicated sunlight exposure as possible treatment for NNJ. The majority (62.5\% or $20 / 32)$ of mothers with prior experience of a jaundiced infant attributed NNJ to malaria/fever, and $34.4 \%(11 / 32)$ did not ascribe NNJ to any specific causes. Three quarters (24/32) of this group of mothers cited death and/or disability as possible outcomes of NNJ.

\section{Predictors of prior knowledge of NNJ and care-seeking practices}

The first regression model (Table 4) showed that mothers who were significantly more likely to have had prior knowledge of NNJ among all the respondents were those with 2 or more children (AOR:4.05; CI:1.75-9.36), those with tertiary education (AOR:1.91; CI:1.01-3.61), and those residing in Lagos (AOR:2.96; CI:1.10-7.97). The second model suggests that multi-parous mothers (AOR:2.38; CI:1.27-4.46) and those with tertiary education (AOR:1.92; CI:1.21-3.05) were also significantly more likely to recognise an infant with jaundice accurately. In the third model, mothers whose source of information about NNJ was a health worker compared to friends, neighbours or relations that are non-health workers were $40 \%$ less likely to resort to the use of potentially harmful substances or therapies for an infant with jaundice (OR:0.60; CI:0.39-0.92). The final model also showed that this group of mothers was significantly more likely in the future to seek hospital treatment for an infant suspected with jaundice (OR:1.88; CI:1.20-2.95). Ethnicity, religion or residential type was not predictive of maternal knowledge of or experience with NNJ. Accurate recognition of NNJ, self-treatment and planned future hospital visit for NNJ were independent of the residential location of the mothers. No factor was also found to be predictive of mothers with prior experience of a jaundiced infant that may not seek hospital care for a future NNJ episode. Maternal age was not considered for inclusion into any of the models as almost $90 \%$ of the respondents were within a single age bracket. All models were satisfactorily calibrated as demonstrated by HosmerLemeshow test results.

\section{Discussion}

Our study builds on the substantial body of evidence in the literature on the seemingly intractable but avoidable 
Table 2 Knowledge of NNJ among mothers attending routine prenatal clinics in Nigeria $(\mathbf{n}=\mathbf{4 3 1})$

\begin{tabular}{|c|c|c|c|c|}
\hline Responses & $\begin{array}{c}\text { Abuja } \\
\mathrm{n}=85(\%)\end{array}$ & $\begin{array}{c}\text { Lagos } \\
n=136(\%)\end{array}$ & $\begin{array}{l}\text { Port Harcourt } \\
n=210(\%)\end{array}$ & $\begin{array}{l}\text { Total } \\
\text { n (\%) }\end{array}$ \\
\hline \multicolumn{5}{|l|}{ Heard about jaundice from } \\
\hline Friend/Neighbour & $15(17.6)$ & $37(27.2)$ & $46(21.9)$ & $98(22.7)$ \\
\hline Health worker & $57(67.1)$ & $61(44.9)$ & $131(62.4)$ & $249(57.8)$ \\
\hline Relations & $5(5.9)$ & $16(11.8)$ & $12(5.7)$ & $33(7.7)$ \\
\hline Media & $1(1.2)$ & $5(3.7)$ & $7(3.3)$ & $13(3.0)$ \\
\hline Other & $7(8.2)$ & $17(12.5)$ & $14(6.7)$ & $38(8.8)$ \\
\hline \multicolumn{5}{|c|}{ Can recognise baby with jaundice } \\
\hline No & $17(20.0)$ & $47(34.6)$ & $58(27.6)$ & $122(28.3)$ \\
\hline Yes & $68(80.0)$ & $89(65.4)$ & $152(72.4)$ & $309(71.7)$ \\
\hline \multicolumn{5}{|l|}{ Where to look for in the baby } \\
\hline Eye, body or skin & $68(80.0)$ & $89(65.4)$ & $152(72.4)$ & $309(71.7)$ \\
\hline Not stated & $17(20.0)$ & $47(34.6)$ & $58(27.6)$ & $122(28.3)$ \\
\hline \multicolumn{5}{|l|}{ What would be seen in baby } \\
\hline Yellowish discolouration & $53(62.4)$ & $75(55.1)$ & $142(67.6)$ & $270(62.6)$ \\
\hline Other & $13(15.3)$ & $11(8.1)$ & $10(4.8)$ & $34(7.9)$ \\
\hline Not stated & $19(22.4)$ & $50(36.8)$ & $58(27.6)$ & $127(29.5)$ \\
\hline \multicolumn{5}{|c|}{ Possible effects of severe jaundice in a baby } \\
\hline Poor feeding & $8(9.4)$ & $28(20.6)$ & $58(27.6)$ & $94(21.8)$ \\
\hline Irritable & $4(4.7)$ & $12(8.8)$ & $11(5.2)$ & $27(6.3)$ \\
\hline Abnormal cry & $15(17.6)$ & $12(8.8)$ & $22(10.5)$ & $49(11.4)$ \\
\hline Abnormal body stretching & $6(7.1)$ & $12(8.8)$ & $12(5.7)$ & $30(7.0)$ \\
\hline Abnormal eye movement & $9(10.6)$ & $15(11.0)$ & $16(7.6)$ & $40(9.3)$ \\
\hline Other & $7(8.2)$ & $2(1.5)$ & $6(2.9)$ & $15(3.5)$ \\
\hline Not stated & $36(42.4)$ & $55(40.4)$ & $85(40.5)$ & $176(40.7)$ \\
\hline \multicolumn{5}{|l|}{ Possible dangers of jaundice } \\
\hline Death & $22(25.9)$ & $71(52.2)$ & $65(31.0)$ & $158(36.6)$ \\
\hline Disability & $30(35.3)$ & $21(15.4)$ & $49(23.3)$ & $100(23.2)$ \\
\hline Death/Disability & $7(8.2)$ & $13(9.6)$ & $36(17.1)$ & $56(13.0)$ \\
\hline Other & $3(3.5)$ & $3(2.2)$ & $9(4.3)$ & $15(3.5)$ \\
\hline Not stated & $23(27.1)$ & 28 (20.6) & $51(24.3)$ & $102(23.7)$ \\
\hline \multicolumn{5}{|l|}{ Possible causes of jaundice } \\
\hline Infections & $15(17.6)$ & $2(1.5)$ & $9(4.3)$ & $26(6.0)$ \\
\hline Malaria/Fever & $23(27.1)$ & $31(22.8)$ & $74(35.2)$ & $128(29.7)$ \\
\hline Prematurity & $0(0.0)$ & $0(0.0)$ & $6(2.9)$ & $6(1.4)$ \\
\hline ABO/Rhesus incompatibility & $0(0.0)$ & $1(0.7)$ & $2(1.0)$ & $3(0.7)$ \\
\hline Others & $18(21.2)$ & $11(8.8)$ & $27(12.9)$ & $56(13.0)$ \\
\hline Not stated & $29(34.1)$ & $91(66.9)$ & $92(43.8)$ & $212(49.2)$ \\
\hline \multicolumn{5}{|l|}{ Planned place of delivery } \\
\hline Same hospital & $51(60.0)$ & $113(83.1)$ & $158(75.2)$ & $322(74.7)$ \\
\hline Other public hospital & $20(23.5)$ & $20(14.7)$ & $27(12.9)$ & $67(15.5)$ \\
\hline Private hospital & $14(16.5)$ & $3(2.2)$ & $21(10.0)$ & $38(8.8)$ \\
\hline Outside hospital & $0(0.0)$ & $0(0.0)$ & $4(1.9)$ & $4(0.9)$ \\
\hline
\end{tabular}


Table 2 Knowledge of NNJ among mothers attending routine prenatal clinics in Nigeria $(n=431)(C o n t i n u e d)$

\begin{tabular}{|c|c|c|c|c|}
\hline \multicolumn{5}{|c|}{ Possible use of haemolytic substances } \\
\hline Dusting powder & $23(27.1)$ & 47 (34.6) & $62(29.5)$ & $132(30.6)$ \\
\hline Robb mentholated cream & $17(20.0)$ & $9(6.6)$ & $13(6.2)$ & $39(9.0)$ \\
\hline Eucalyptus oil & $10(11.8)$ & $28(20.6)$ & $15(7.1)$ & $53(12.3)$ \\
\hline Camphor on clothes & $0(0.0)$ & $5(3.7)$ & $12(5.7)$ & $17(3.9)$ \\
\hline Not stated & $35(41.2)$ & 47 (34.6) & $108(51.4)$ & $190(44.1)$ \\
\hline
\end{tabular}

burden of severe NNJ in Nigeria by exploring a critical pathway to appropriate care-seeking behaviour among pregnant mothers [4,5,10-21]. This is also against the backdrop of recent findings from a national survey of paediatricians in the country which highlighted the apparent omission of $\mathrm{NNJ}$ in the current global child health priorities for newborn care for Nigeria and comparable developing countries [24].

This study suggests that there is a high level of awareness of NNJ among women attending antenatal clinics

Table 3 Experience and planned action by mothers on infants with jaundice $(n=431)$

\begin{tabular}{|c|c|c|c|c|}
\hline Responses & $\begin{array}{c}\text { Abuja } \\
n=85 \text { (\%) }\end{array}$ & $\begin{array}{c}\text { Lagos } \\
n=136(\%)\end{array}$ & $\begin{array}{l}\text { Port Harcourt } \\
n=210(\%)\end{array}$ & $\begin{array}{l}\text { Total } \\
\text { n (\%) }\end{array}$ \\
\hline \multicolumn{5}{|l|}{ Ever had baby with jaundice } \\
\hline No & $56(65.9)$ & $107(78.7)$ & $140(66.7)$ & $303(70.3)$ \\
\hline Yes & $29(34.1)$ & $29(21.3)$ & 70 (33.3) & $128(29.7)$ \\
\hline \multicolumn{5}{|c|}{ Who first detected the baby with jaundice } \\
\hline Self & $12(14.1)$ & $6(4.4)$ & $22(10.5)$ & $40(9.3)$ \\
\hline Relation/Neighbour & $3(3.5)$ & $9(6.6)$ & $18(8.6)$ & $30(7.0)$ \\
\hline Doctor/Nurse & $14(16.5)$ & $13(9.6)$ & $30(14.3)$ & $57(13.2)$ \\
\hline Not stated & $0(0.0)$ & $1(0.7)$ & $0(0.0)$ & $1(0.2)$ \\
\hline Not applicable & $56(65.9)$ & $107(78.7)$ & $140(66.7)$ & $303(70.3)$ \\
\hline \multicolumn{5}{|l|}{ Action taken/treatment } \\
\hline Hospital admission & $23(27.1)$ & $17(12.5)$ & $15(14.3)$ & $70(16.2)$ \\
\hline Sunlight exposure & $5(5.9)$ & $5(3.7)$ & $28(13.3)$ & $38(8.8)$ \\
\hline Antibiotics & $0(0.0)$ & $0(0.0)$ & $3(0.7)$ & $3(0.7)$ \\
\hline Breast feeding & $0(0.0)$ & $1(0.7)$ & $1(0.5)$ & $2(0.5)$ \\
\hline Pawpaw & $1(1.2)$ & $0(0.0)$ & $0(0.0)$ & $1(0.2)$ \\
\hline Not stated & $0(0.0)$ & $6(4.4)$ & $8(3.8)$ & $14(3.2)$ \\
\hline Not applicable & $56(65.9)$ & $107(78.7)$ & $140(66.7)$ & $303(70.3)$ \\
\hline \multicolumn{5}{|l|}{ Final outcome } \\
\hline Baby died & $1(1.2)$ & $1(0.7)$ & $7(3.3)$ & $9(2.1)$ \\
\hline Baby recovered fully & $28(32.9)$ & $23(16.9)$ & $63(30.0)$ & $114(26.5)$ \\
\hline Baby survived with problems & $0(0.0)$ & $3(2.2)$ & $0(0.0)$ & $3(0.7)$ \\
\hline Not stated & $0(0.0)$ & $2(1.5)$ & $0(0.0)$ & $2(0.5)$ \\
\hline Not applicable & $56(65.9)$ & $107(78.7)$ & $140(66.7)$ & $303(70.3)$ \\
\hline \multicolumn{5}{|l|}{ Possible future action } \\
\hline Go to hospital & $67(78.8)$ & $91(66.9)$ & $145(69.0)$ & $303(70.3)$ \\
\hline Sunlight exposure & $11(12.9)$ & $1(0.7)$ & 39 (18.6) & $51(11.8)$ \\
\hline Antibiotics & $2(2.4)$ & $0(0.0)$ & $1(0.5)$ & $3(0.7)$ \\
\hline Exclusive breastfeeding & $0(0.0)$ & $1(0.7)$ & $1(0.5)$ & $2(0.5)$ \\
\hline Not stated & $5(5.9)$ & 43 (31.6) & $24(11.4)$ & $72(16.7)$ \\
\hline
\end{tabular}


Table 4 Logistic regression models predicting prior knowledge of NNJ, accurate recognition of NNJ, self-treatment and planned future hospital visit for NNJ treatment

\begin{tabular}{|c|c|c|c|c|}
\hline \multirow[t]{2}{*}{ Factors } & Model 1 & Model 2 & Model 3 & Model 4 \\
\hline & AOR $(95 \% \mathrm{Cl})$ & AOR $(95 \% \mathrm{Cl})$ & AOR $(95 \% \mathrm{Cl})$ & AOR $(95 \% \mathrm{Cl})$ \\
\hline \multicolumn{5}{|l|}{ Parity } \\
\hline 0 & Reference & Reference & Reference & Reference \\
\hline 1 & $1.76(0.78-3.96)$ & $1.48(0.80-2.76)$ & $1.58(0.85-2.96)$ & $1.86(0.98-3.55)$ \\
\hline 2 or more & $4.05(1.75-9.36)^{* * *}$ & $2.38(1.27-4.46)^{* *}$ & $1.64(0.89-3.03)$ & $1.63(0.87-3.04)$ \\
\hline \multicolumn{5}{|l|}{ Ethnicity } \\
\hline Hausa & Reference & Reference & Reference & Reference \\
\hline Ibo & $1.11(0.42-2.97)$ & $0.94(0.42-2.10)$ & $0.91(0.45-1.83)$ & $1.07(0.50-2.29)$ \\
\hline Yoruba & $1.44(0.49-4.25)$ & $0.55(0.24-1.24)$ & $1.47(0.68-3.16)$ & $1.13(0.50-2.58)$ \\
\hline Others & $1.49(0.56-3.98)$ & $0.75(0.34-1.63)$ & $0.81(0.41-1.62)$ & $0.90(0.43-1.91)$ \\
\hline \multicolumn{5}{|l|}{ Religion } \\
\hline Christianity & Reference & Reference & Reference & Reference \\
\hline Islam & $0.69(0.23-2.07)$ & $1.68(0.72-3.90)$ & $1.08(0.49-2.35)$ & $2.04(0.83-5.01)$ \\
\hline \multicolumn{5}{|l|}{ Education } \\
\hline Non-tertiary & Reference & Reference & Reference & Reference \\
\hline Tertiary & $1.91(1.01-3.61)^{*}$ & $1.92(1.21-3.05)^{* *}$ & $0.78(0.51-1.21)$ & $1.20(0.74-1.92)$ \\
\hline \multicolumn{5}{|l|}{ Residential type } \\
\hline Self-contained & Reference & Not Applicable & Reference & Reference \\
\hline Shared & $0.71(0.35-1.41)$ & & $1.29(0.76-2.19)$ & $0.70(0.41-1.22)$ \\
\hline \multicolumn{5}{|l|}{ Location } \\
\hline Abuja & Reference & Reference & Reference & Reference \\
\hline Lagos & $2.96(1.10-7.97)^{*}$ & $0.60(0.30-1.23)$ & $1.33(0.70-2.54)$ & $0.67(0.33-1.40)$ \\
\hline Port Harcourt & $1.15(0.53-2.48)$ & $0.70(0.37-1.34)$ & $0.74(0.43-1.30)$ & $0.70(0.36-1.35)$ \\
\hline \multicolumn{5}{|l|}{ Source of information } \\
\hline Non health worker & Not applicable & Reference & Reference & Reference \\
\hline Health worker & & $1.09(0.69-1.73)$ & $0.60(0.39-0.92)^{*}$ & $1.88(1.20-2.95)^{* *}$ \\
\hline Hosmer-Lemeshow Test & $p=0.235$ & $p=0.395$ & $p=0.769$ & $p=0.552$ \\
\hline
\end{tabular}

${ }^{*} \mathrm{p}<0.05 ;{ }^{* *} \mathrm{p}<0.01 ;{ }^{* * *} \mathrm{p}<001 ; \mathrm{AOR}=$ adjusted odds ratio; $\mathrm{Cl}=$ confidence interval.

Model 1: Factors predicting women who are most likely to have previously heard about neonatal jaundice.

Model 2: Factors predicting ability to recognise the possible occurrence of NNJ.

Model 3: Factors predicting self-treatment with potentially harmful substances.

Model 4: Factors predicting women who are likely to seek or advise hospital care for an infant with NNJ.

in tertiary hospitals with or without a prior personal experience of a jaundiced infant. This is consistent with findings in similar studies in Nigeria and other developing countries in which awareness of NNJ among women ranges from $86-100 \%$ prior to delivery $[19,20,25]$, shortly after delivery [26], or while presenting in hospitals for newborn care [21,27]. About 37\% of women who indicated an awareness of $\mathrm{NNJ}$ in our study were unlikely to accurately recognise the onset of the condition. One study in Nigeria reported a rate as high as $43 \%$ in this group of women [20], while others have reported rates as low as $23 \%[19,27]$. Multiparous mothers were fourtimes more likely to have a knowledge of NNJ than firsttime mothers while women with tertiary education were almost twice more likely to be aware than women with less than tertiary education. The awareness among multiparous and highly educated mothers was also associated with accurate recognition of $\mathrm{NNJ}$ in the affected infants which is corroborated by findings in comparable studies in Nigeria and Turkey $[19,21,28]$. Mothers residing in Lagos appear to have the greatest advantage as they were almost three-times more likely to have heard about NNJ than say mothers residing in Abuja. This may be attributed to the fact that the city only ceded its status as the federal capital since independence in 1960 to Abuja in 1991 and still remains the financial/commercial nerve-centre for the country. However, these mothers were not significantly more likely to recognise NNJ than those 
outside Lagos suggesting that geographical location had little or no impact on mothers' accurate recognition of a jaundiced infant. While a high percentage of mothers also recognised the physical symptoms of NNJ, any suggestion of high NNJ awareness among any groups of women must not be misconstrued as ability to recognise the onset of the condition or assurance of appropriate care-seeking decision. A nation-wide campaign to eliminate the differences in the level of awareness across the country is warranted. Perhaps, the greatest challenge is in disseminating this education to the vast majority of women in Nigeria who presently do not deliver in hospitals [16].

It is insightful that many mothers still indicated the use of traditional and potentially harmful therapies regardless of the planned delivery in a health facility for their current pregnancy. This would suggest that the dangers of such practice are yet to be well-appreciated across the country. Some mothers may, in fact, nurse the belief that these traditional therapies are complementary to hospital treatment as "first-aid". Our study suggests that the quality and source of education on NNJ may, in fact, explain this tendency or practice in the affected mothers. Mothers who derived their knowledge of NNJ from health workers were significantly less inclined to self-treatment and more likely to seek hospital treatment for their jaundiced infants. Thus the observed high level of awareness reported in this and other studies must also not distract from the underlying risks associated with sources of NNJ education that are not health workers. This finding is reassuring as some professional health workers have been blamed for encouraging or perhaps not discouraging direct sunlight exposure as possible treatment for NNJ which is still common in many developing countries $[25,27,29,30]$. One study in Nigeria reported that $50.7 \%$ of mothers who claimed awareness of NNJ indicated exposure to sunlight as their preferred treatment option [27]. Another from Malaysia showed that $83.1 \%$ of the mothers from different races practised the sunning of their jaundiced infants [25]. However, there is emerging evidence on the possible utilization of specially "filtered" sunlight phototherapy using tinted films for the safe and effective treatment of NNJ especially in resource-limited communities without (steady) electricity supply to support conventional electric-powered phototherapy units [31]. This holds promise as an improvement on the pioneering effort of an indigenous neonatologist who introduced a "sunshine phototherapy cot" for treatment of mild NNJ in primary health care centres [27,32].

Our study, like prior reports, demonstrates the need for focused educational campaign among the most vulnerable groups of mothers (particularly first-time mothers and those without tertiary education) prior to delivery to improve their knowledge of the risk factors for severe NNJ, the accurate detection of its onset, avoidance of harmful therapies, the benefits of early and appropriate intervention, as well as the potential consequences for case fatality or life-long detrimental effects on the survivors and their families. In fact, even where requisite services are available, the life-time rehabilitation costs for the associated developmental impairments like cerebral palsy, deafness, autism and epilepsy are far beyond the reach of most families in these settings. This consideration itself should provide the impetus for needed preventive action by policy makers at all levels of health care delivery. Efforts to promote proper careseeking behaviour by mothers must nonetheless be backed and sustained by the provision of effective treatment for those who present in hospitals especially after early (<48hours) hospital discharge which is quite common. For example, there are several reports on the poor quality of treatment offered even in tertiary hospitals as a result of ineffective phototherapy, avoidable exchange blood transfusions and lack of reliable devices for real-time bilirubin monitoring [17,33,34]. This situation sometimes weakens the resolve and enthusiasm of some health workers to promote hospital treatment aggressively, thereby inadvertently fostering recourse to "alternative" traditional therapies including indiscriminate (mis)use of antibiotics such as Ampiclox ${ }^{\oplus}$ and gentamycin. Our study also suggests that about one quarter of mothers with prior experience with a jaundiced infant may not seek hospital care but resort to self-treatment of perceived malaria/fever as the underlying cause of NNJ. We were unable to establish any specific socio-demographic predictors for this group of mothers.

Besides the possible influence of cultural beliefs and unfavourable perception of hospital care, it was also unclear why maternal education had a significant impact on knowledge and accurate recognition of NNJ but not on recourse to self-treatment or planned future hospital visit for a jaundiced infant. This is against the backdrop of other reports from one centre in Southwest Nigeria that associated high maternal education with appropriate health-seeking behaviour for NNJ [21]. Additionally, while another study from Southeast Nigeria found statistically significant difference between mothers with primary education and those with tertiary education with regards to correct perception of NNJ treatment, no significant difference was found between those with secondary and tertiary education [27]. While further research would still be useful to understand fully why women with prior experience of a jaundiced infant will resort to self-treatment and will not seek future hospital care for the same condition, maternal education by health workers must necessarily be complemented with improvement in the quality of hospital care. Some practical and low-cost approaches to making phototherapy more effective which can be readily implemented in resourceconstrained settings have been documented [5,35]. 
A number of limitations of this hospital-based study among urban women are worth noting. For instance, notwithstanding the multi-centre design, it is difficult to ascertain the extent to which the findings in this study can be generalised to the entire country especially among the rural population. We recognise that the exact course of future action that participants of this study would take when confronted with a life case of an infant with jaundice may differ from the information provided in this report. There is also the likelihood of selection bias for the three centres and locations used for this study. Nevertheless, the key findings in this study are consistent with prior reports from Nigeria and transcend cultural and religious affiliations.

\section{Conclusion}

There is a high awareness of NNJ generally among Nigerian mothers and a good proportion especially those who are multiparous or with tertiary education are likely to recognise the onset of the condition in their infants accurately and seek hospital care owing mainly to the education received from professional health workers. Notwithstanding the awareness of NNJ, some mothers, including those with prior experience with a jaundiced infant, are still likely to resort to self-treatment with potentially harmful therapies. While concerted efforts to improve care-seeking practices among mothers are warranted, it is (ethically) imperative for hospital administrators and service providers to ensure that all requisite facilities are optimally functional to protect every infant from the fatal or life-long complications of severe NNJ if and when mothers make the right decision to seek hospital care timely for their jaundiced infants.

\section{Additional file}

\section{Additional file 1: Multi-centre maternal survey on neonatal jaundice.}

\section{Competing interests}

The authors declare that they have no competing interests.

\begin{abstract}
Authors' contributions
CVE and NKE conceived and designed the pilot study that formed the basis for the survey instrument used in this study. The final instrument was designed by $\mathrm{BOO}$ and reviewed by CVE, MMY and ROU who also personally supervised data collection from the participating centres. BOO analysed the data and drafted the manuscript. All other authors critically reviewed the draft, read and approved the final manuscript.
\end{abstract}

\section{Acknowledgements}

The authors are grateful for the very helpful comments on the survey instrument by Tina Slusher (USA) and Samuel Olowe, Emeritus Professor of Paediatrics (Nigeria)

\section{Funding}

No funding was received by any of the authors for this work.

\section{Author details}

${ }^{1}$ Department of Paediatrics, Lagos University Teaching Hospital, Surulere, Lagos, Nigeria. ${ }^{2}$ Department of Paediatrics and Child Health, University of Port Harcourt Teaching Hospital, Port Harcourt, Nigeria. ${ }^{3}$ Department of Paediatrics, National Hospital, Abuja, Nigeria. ${ }^{4}$ Centre for Healthy Start Initiative, Dolphin Estate, Ikoyi, Lagos, Nigeria.

Received: 28 May 2013 Accepted: 25 April 2014

Published: 28 April 2014

\section{References}

1. The Young Infants Clinical Signs Study Group: Clinical signs that predict severe illness in children under age 2 months: a multicentre study. Lancet 2008, 371:135-142.

2. English M, Ngama M, Musumba C, Wamola B, Bwika J, Mohammed S, Ahmed M, Mwarumba S, Ouma B, McHugh K, Newton C: Causes and outcome of young infant admissions to a Kenyan district hospital. Arch Dis Child 2003, 88:438-443.

3. Kilic S, Tezcan S, Tascilar E, Cakir B, Aydin HI, Hasde M, Gökçay E: Morbidity and mortality characteristics of infants hospitalised in the pediatrics department of the largest Turkish military hospital in 2001. Military Med 2005, 70:48-51.

4. Ezeaka VC, Ogunbase AO, Awogbemi OT, Grange AO: Why our children die: a review of paediatric mortality in a tertiary centre in Lagos, Nigeria. Nig Qt J Hosp Med 2003, 13:17-21.

5. Slusher TM, Olusanya BO: Neonatal Jaundice in Low-and Middle-Income Countries. In Care of the Jaundiced Neonate. Edited by Stevenson DK, Maisels J, Watchko J. New York, NY: McGraw-Hill; 2012:263-273. Chapter 13.

6. Committee on Nervous System Disorders in Developing Countries (CNSDDC), Board on Global Health: Neurological, psychiatric and developmental disorders: meeting the challenge in the developing world. Washington DC: National Academy Press; 2001

7. Mwaniki MK, Atieno M, Lawn JE, Newton CR: Long-term neurodevelopmental outcomes after intrauterine and neonatal insults: a systematic review. Lancet 2012, 379:445-452.

8. Brethauer M, Carey L: Maternal experience with neonatal jaundice. MCN Am J Matern Child Nurs 2010, 35:8-14

9. Madlon-Kay DJ: Recognition of the presence and severity of newborn jaundice by parents, nurses, physicians, and icterometer. Pediatrics 1997, 100(3):E3.

10. Olowe SA, Ransome-Kuti O: The risk of jaundice in glucose-6-phosphate dehydrogenase deficient babies exposed to menthol. Acta Paediatr Scand 1980, 69:341-345.

11. Duggan MB, Ogala W: Cerebral palsy in Nigeria: a report from Zaria. Ann Trop Paediatr 1982, 2:7-11.

12. Izuora Gl: Aetiology of mental retardation in Nigerian children around Enugu. Cent Afr J Med 1985, 31:13-16.

13. Slusher TM, Vreman HJ, McLaren DW, Lewison LJ, Brown AK, Stevenson DK: Glucose-6-phosphate dehydrogenase deficiency and carboxy-hemoglobin concentrations associated with bilirubin-related morbidity and death in Nigerian infants. J Pediatr 1995, 126:102-108.

14. Ogunlesi TA, Dedeke IO, Adekanmbi AF, Fetuga MB, Ogunfowora OB: The incidence and outcome of bilirubin encephalopathy in Nigeria: a bi-centre study. Niger J Med 2007, 16:354-359.

15. Olusanya $\mathrm{BO}$, Somefun $\mathrm{AO}$ : Sensorineural hearing loss in infants with neonatal jaundice in a developing country: a community-based study. Ann Trop Paediatr 2009, 29:119-128.

16. Olusanya BO, Akande AA, Emokpae A, Olowe SA: Infants with severe neonatal jaundice in Lagos, Nigeria: incidence, correlates and hearing screening outcomes. Trop Med Int Health 2009, 14:301-310.

17. Owa JA, Ogunlesi TA: Why we are still doing so many exchange blood transfusion for neonatal jaundice in Nigeria. World J Pediatr 2009, 5:51-55.

18. Oyebola DD: Care of the neonate and management of neonatal jaundice as practised by Yoruba traditional healers of Nigeria. J Trop Pediatr 1983, 29:18-22.

19. Egube BA, Ofili AN, Isara AR, Onakewhor JU: Neonatal jaundice and its management: knowledge, attitude, and practice among expectant mothers attending antenatal clinic at University of Benin Teaching Hospital, Benin City, Nigeria. Niger J Clin Pract 2013, 16:188-194.

20. Ogunfowora $O B$, Adefuye PO, Fetuga MB: What do expectant mothers know about neonatal jaundice? Int Electron J Health Educ 2006, 9:134-140. 
21. Ogunlesi TA, Ogunlesi FB: Family socio-demographic factors and maternal obstetric factors influencing appropriate health-care seeking behaviours for newborn jaundice in Sagamu, Nigeria. Matern Child Health J 2012, 16:677-684.

22. World Medical Association: World medical association declaration of Helsinki: ethical principles for medical research involving human subjects. Bull World Health Organ 2001, 79:373-374.

23. Sun GW, Shook TL, Kay GL: Inappropriate use of bivariable analysis to screen risk factors for use in multivariable analysis. J Clin Epidemiol 1996, 49:907-916.

24. Olusanya BO, Ezeaka CV, Ajayi-Obe EK, Mukhtar-Yola M, Ofovwe GE: Paediatricians' perspectives on global health priorities for newborn care in a developing country: a national survey from Nigeria. BMC Int Health Hum Rights 2012, 12:9.

25. Boo NY, Gan CY, Gian YW, Lim KS, Lim MW, Krishna-Kumar H: Malaysian mothers' knowledge \& practices on care of neonatal jaundice. Med J Malaysia 2011, 66:239-243.

26. Khalesi N, Rakhshani F: Knowledge, attitude and behaviour of mothers on neonatal jaundice. J Pak Med Assoc 2008, 58:671-674.

27. Eneh AU, Ugwu RO: Perception of neonatal jaundice among women attending children out patient and immunization clinics of the UPTH Port Harcourt. Niger J Clin Pract 2009, 12:187-191.

28. Sutcuoglu S, Dursun S, Halicioglu O, Ozturk C, Akman S, Yaprak I, Ozer E: Evaluation of maternal knowledge level about neonatal jaundice. J Matern Fetal Neonatal Med 2012, 25:1387-1389.

29. Harrison SL, Buettner PG, MacLennan R: Why do mothers still sun their infants? J Paediatr Child Health 1999, 35:296-299.

30. Aladag N, Filiz TM, Topsever P, Gorpelioglu S: Parents' knowledge and behaviour concerning sunning their babies; a cross-sectional, descriptive study. BMC Pediatr 2006, 6:27.

31. Slusher TM, Vreman HJ, Olusanya BO, Wong RJ, Brearley AM, Vaucher YE, Stevenson DK: Safety and efficacy of filtered sunlight in treatment of jaundice in African neonates. Pediatrics 2014. in press.

32. Olowe SA: Sunshine photherapy cot: utilization of sunlight for phototherapy. Nig J Paed 1985, 12:69-70.

33. Owa JA, Adebami OJ, Fadero FF, Slusher TM: Irradiance readings of phototherapy equipment: Nigeria. Indian J Pediatr 2011, 78:996-998.

34. Bhutani VK, Cline BK, Donaldson KM, Vreman HJ: The need to implement effective phototherapy in resource-constrained settings. Semin Perinatol 2011, 35:192-197.

35. Cline BK, Vreman HJ, Faber K, Lou H, Donaldson KM, Amuabunosi E, Oforwe G, Bhutani VK, Olusanya BO, Slusher TM: Phototherapy device effectiveness in Nigeria: irradiance assessment and potential for improvement. J Trop Pediatr 2013, 59:321-325.

\section{doi:10.1186/1472-6963-14-192}

Cite this article as: Ezeaka et al:: Pattern and predictors of maternal care-seeking practices for severe neonatal jaundice in Nigeria: a multi-centre survey. BMC Health Services Research 2014 14:192.

\section{Submit your next manuscript to BioMed Central and take full advantage of:}

- Convenient online submission

- Thorough peer review

- No space constraints or color figure charges

- Immediate publication on acceptance

- Inclusion in PubMed, CAS, Scopus and Google Scholar

- Research which is freely available for redistribution

Submit your manuscript at www.biomedcentral.com/submit 